\title{
EMG Related Anxiety and Pain: A Prospective Study
}

\author{
Mohammed M.S. Jan, Murray Schwartz, and Timothy J. Benstead
}

\begin{abstract}
Background: Electromyography (EMG) is a useful test, but unfortunately also painful. We frequently encounter patients who worry about its painful nature, but tolerate it very well. Objectives: We evaluated anxiety levels of patients referred for EMG to explore the possible correlating and contributing factors to high anxiety. Methods: A structured questionnaire, including the State-Trait Anxiety Inventory was completed by patients immediately before EMG testing. Emergency, hospitalized, and seriously ill patients were excluded. Results: Seventy-nine cases with ages ranging from 19-72 years (mean 43) were included. Thirty-five (44\%) patients had a high pre-test anxiety level. The likelihood of high anxiety was increased if the patient was worried about the test $(\mathrm{p}<0.001)$ or about other issues unrelated to the test or underlying diagnosis $(\mathrm{p}<0.001)$, or was taking an anti-psychotic or anxiolytic drug $(\mathrm{p}=0.008)$. The degree or source of knowledge regarding the test procedure, did not affect the pre-test anxiety level. Conclusions: The information about EMG testing received by patients in this group did not affect pre-test anxiety levels. The patient's expectations regarding the test did influence anxiety levels and this may reflect generalized anxiety regarding testing procedures or misinformation regarding the nature of the test, as patients in general reported a better than anticipated experience following the test.
\end{abstract}

RÉSUMÉ: Anxiété et douleur reliées à l'ÉMG: une étude prospective. Introduction: L'électromyographie (ÉMG) est un examen utile mais douloureux. Nous rencontrons souvent des patients qui s'inquiètent que l'examen soit douloureux, mais qui le tolèrent très bien. Objectifs: Nous avons évalué le niveau d'anxiété de patients référés pour un ÉMG afin d'explorer les facteurs possibles ayant une corrélation et contribuant à un niveau élevé d'anxiété. Méthodes: Un questionnaire structuré, incluant le State-Trait Anxiety Inventory a été complété par les patients immédiatement avant de subir un ÉMG. Les patients se présentant à l'urgence, les patients hospitalisés et ceux qui étaient gravement malades ont été exclus. Résultats: Soixante-dix-sept patients dont l'âge variait entre 19 et 72 ans (moyenne 43) ont participé à l'étude. Trente-cinq patients (44\%) avaient un niveau d'anxiété élevé avant le test. La probabilité que le patient soit très anxieux était plus élevée si le patient était inquiet à propos du test $(\mathrm{p}<0.001)$ ou pour d'autres raisons non reliées au test ou au diagnostic ( $\mathrm{p}<0.001$ ), ou qu'il prenait une médication antipsychotique ou anxiolytique $(\mathrm{p}=0.008)$. Le degré ou la source des connaissances sur le test n'affectait pas le niveau d'anxiété prétest. Conclusions: L'information sur l'ÉMG reçue par les patients de ce groupe n'influençait pas le niveau d'anxiété pré-test. Les attentes des patients concernant le test ont influencé le niveau d'anxiété et ceci peut refléter une anxiété généralisée envers le test ou une information erronée sur la nature du test, vu que les patients en général ont rapporté que leur expérience du test avait été meilleure qu'ils ne l'avaient anticipée.

Can. J. Neurol. Sci. 1999; 26: 294-297

Electromyography (EMG) is a useful diagnostic test for evaluation of neuromuscular disorders. Unfortunately, patients may find it painful, particularly when needle EMG is performed. We frequently encounter patients who worry excessively about the painful nature of the test. Sources of this belief could be a previous difficult EMG experience, or through information received from the referring physician, family, or friends. Most patients in our experience tolerate the test well, and many mention at the end that it was much better than they expected.

There is no evidence in the literature to support the belief that EMG is more stressful than other diagnostic tests. Details of the anxiety profile of patients undergoing EMG, and its sources prior to testing have received limited attention. This information would be important for appropriate patient counseling prior to the test. In one study, high trait anxiety was found to be predictive of EMG related pain. ${ }^{1}$

To determine the anxiety profile of patients undergoing EMG, we used the State-Trait Anxiety Inventory, which is a simple self evaluation questionnaire that quantitatively measures the anxiety

\footnotetext{
From the Division of Neurology and Department of Psychology (MS), QEII Health Sciences Centre and Dalhousie University Medical School, Halifax, Nova Scotia, Canada (MMSJ, TJB)

RECEIVEDJANUAR Y 12, 1999. ACCEPTED INFINALFORMMA Y 5, 1999

Reprint requests to: Timothy J Benstead, Division of Neurology, QEII Health Sciences Centre, 1796 Summer Street, Halifax, Nova Scotia, Canada B3H 3A7
} 
level with a series of 40 questions. $^{2}$ It is a well tested questionnaire that is normalized to a national standard. ${ }^{3}$

Our objectives were to study the level and sources of anxiety immediately before EMG testing and determine the possible correlating factors to high anxiety.

\section{MeThods}

A cohort of consecutive adult patients coming for EMG were included prospectively. Patients were excluded from this study if they were seriously ill or had a disturbed level of consciousness at the time of the examination. As well, all emergency and hospitalized cases were excluded. An informed consent was completed by all patients. The questionnaire and study design were approved by the hospital ethics committee.

The State-Trait Anxiety Inventory questionnaire was completed by the patients immediately before EMG testing. ${ }^{2}$ This consists of two parts (20 questions each) that examines different aspects of the anxiety profile, State and Trait anxiety. State anxiety refers to how the patient feels at the moment of completing the questions, i.e., acute reactions. Trait anxiety refers to relatively stable individual differences in anxiety proneness. The scores are normalized for the demographics, age, and sex of the patient. In accordance with the published data, State-Trait Anxiety Inventory scores are considered elevated if they are more than one standard deviation above the mean for the normal values expected for adult men and women. ${ }^{2}$

Additional questions were asked to examine demographic characteristics, educational level, history of medical or psychiatric illness, sources and levels of information about the test, sources of anxiety and perception of the painful nature of the test. After the questionnaires were completed, and before the EMG was started, the patients received a complete explanation of testing procedures by the EMG laboratory staff. The number of nerves assessed by nerve conduction and muscles by needle EMG, as well as the result of the test were recorded at the end of the test. A final five point question regarding the overall impression about the testing, was completed after the completion of the test. These five points were: much worse than expected, worse than expected, as expected, better than expected, or much better than expected.

Statistical analysis was performed using Epi Info, version $6 .{ }^{4}$ The relationship between the anxiety level and the other variables was examined in $2 \times 2$ tables using chi-square statistics. The magnitude of significant associations is presented as $\mathrm{p}$ values and odds ratios.

\section{RESULTS}

During the study period, 79 eligible cases were included. The age at the time of testing ranged between 19-72 years (mean $43 \pm$ STD 12.6). There were 51 (65\%) females and 28 (35\%) males. Nerve conduction studies were performed on all patients, and 39 (49\%) patients had needle EMG using a standard concentric needle. Only 15 (19\%) patients had a previous EMG, 10 of whom had only one prior test. The highest school grade completed ranged between 6-12 (mean 11). Forty-five (57\%) completed grade 12 , and $28(35 \%)$ had a college or university degree.

A history of other medical illness (other than the indication for EMG) was present in 34 (43\%). Psychiatric or emotional disorders were reported in 19 (24\%) patients, and 19 (24\%) were on an anti-psychotic or anxiolytic drug. Females were 6.5 times more likely to have a psychiatric illness $(\mathrm{p}=0.01)$.

Upon questioning regarding pre-test knowledge about the procedures involved in EMG testing, $26(33 \%)$ reported that they were not informed at all, and only $6(7.6 \%)$ thought that they were very well informed. No factor including educational level correlated with the degree of knowledge. Among those who felt informed, physicians were the commonest source of information (48\%), but $16 \%$ reported having received some information from friends or family members.

Thirty-two (40\%) patients reported being worried about having the test and $46(58 \%)$ were worried about the possible diagnosis that may result from the test. Patients worried about the test were more likely to be worried about the diagnosis $(\mathrm{p}<0.001)$. Fourteen $(18 \%)$ patients stated that they were worried about other issues in their lives, unrelated to the test or possible EMG diagnosis.

Table: Comparison between the two groups with and without high anxiety level

\begin{tabular}{|c|c|c|c|c|c|}
\hline Patients & $35 / 79$ & 44 & $44 / 79$ & 56 & n.s. \\
\hline Female sex & $25 / 51$ & 49 & $26 / 51$ & 51 & n.s. \\
\hline Informed about the test & $23 / 53$ & 43 & $30 / 53$ & 57 & n.s. \\
\hline Not informed about the test & $12 / 26$ & 46 & $14 / 26$ & 54 & n.s. \\
\hline History of psychiatric illness & $12 / 19$ & 63 & $7 / 19$ & 37 & n.s. \\
\hline Worried about the diagnosis & $23 / 46$ & 50 & $23 / 46$ & 50 & n.s. \\
\hline Expected EMG to be painless & $10 / 33$ & 30 & $23 / 33$ & 70 & 0.05 \\
\hline On antipsychotic or anxiolytic & $10 / 12$ & 83 & $2 / 12$ & 17 & 0.008 \\
\hline Worried about the test & $23 / 32$ & 2 & $9 / 32$ & 28 & $<0.001$ \\
\hline
\end{tabular}

n.s. = not significant 
Thirty-five (44\%) patients had an anxiety level more than one standard deviation above the mean for the normal values expected for age and sex. Using this standardized questionnaire, these patients would be regarded as having significantly elevated anxiety levels. The majority of these patients had elevation of both State and Trait anxiety $(n=17)$, while only high State anxiety was noted in 10 patients, and 8 had a high Trait anxiety only. Variables that were compared between those with and without high pre-test anxiety are outlined in the Table. The age and sex ratio was similar in the two groups. The likelihood of a high anxiety level was increased if the patient stated that he or she was worried about the test $(\mathrm{p}<0.001)$. Equal numbers of patients were worried about the EMG diagnosis in the two groups with and without high anxiety. Almost all patients who stated that they were worried about issues other than the test or diagnosis had high anxiety $(93 \%)(\mathrm{p}<0.001)$.

Thirty-three $(42 \%)$ patients had not anticipated the EMG would cause pain and these patients were 2.7 times more likely to have a normal anxiety level (95\% CI 1-8). They were even more likely to be unworried about the test (odds ratio $=5.8,95 \%$ CI 1.8-20). A history of having a previous EMG, concurrent medical illness or psychiatric illness was not correlated with high anxiety levels. As well, the degree or source of knowledge regarding the test prior to arrival at the laboratory, was not associated with differences in the anxiety level. On the other hand, if the patient was taking any anti-psychotic or anxiolytic drug, they were more likely to have high anxiety $(\mathrm{P}=0.008)$.

After the test, $43(54 \%)$ patients felt that the testing experience had been better or much better than they had anticipated. Only $7(9 \%)$ patients felt that the test was worse than expected, and the remaining patients felt that it was as expected. None stated that the test was much worse than expected. Technical difficulties with nerve conduction studies were more common in the group that had found the test worse than expected $(\mathrm{P}=0.007)$. As well, 6 of these 7 patients had needle EMG performed $(\mathrm{p}=0.05)$. Neither the number of nerves (mean 6) or muscles (mean 4) examined correlated with a worse than expected experience.

In our cohort, $46(58 \%)$ had an abnormal EMG result. Neither an abnormal result, nor the diagnosis made correlated with the anxiety level.

\section{Discussion}

Our study confirms that many patients undergoing EMG have high anxiety levels. The likelihood of high anxiety correlated to four main patient factors. The first was feeling worried about the test. Interestingly, although many patients were also worried about the diagnosis, this did not correlate with high anxiety. The second factor was feeling worried about issues other than the test or the diagnosis. This factor was present in only a small percentage of the study population (18\%), but was highly predictive of high anxiety. The third important factor was the anticipation that the test would be painless. Those who believed that the test would not be painful usually had normal anxiety levels and were not worried about the test. Those who thought that EMG would cause pain were just as likely to demonstrate normal anxiety as high anxiety. This suggests that knowledge of the painful nature of the test did not adversely affect patient anxiety levels and did not appear to be as important an issue as simply coming for a test. The last important factor was whether the patient was taking an antipsychotic or anxiolytic drug, as these were more likely to predict high anxiety. Patients with a history of psychiatric illness, but not necessarily being currently treated, did not have significantly higher anxiety. Drug history could be more accurate in identifying active psychiatric disorders.

In our cohort, one third of the patients reported that they were not informed at all about the nature of the test, and only six patients thought that they were very well informed. Information about the test was not sent routinely to patients prior to EMG from our institution, though after the questionnaires were completed the test was explained by EMG staff. The majority of pre-questionnaire information was obtained from the referring physician, but patients also obtained information from family and friends. Khoshpin ${ }^{1}$ noted that high anxiety levels predicted greater EMG pain and found that information about the test can decrease pretest anxiety. ${ }^{1}$ Our study confirmed that high anxiety is common among patients coming for EMG, but found the level of information provided to the patient before the test did not affect anxiety levels either positively or negatively. The study did not directly evaluate whether a standardized disclosure of information about EMG would relieve pretest anxiety, but it is possible that the explanation provided by EMG lab staff prior to performance of the test contributed to the better than expected experience reported by patients. Other investigators have demonstrated that utilizing a standard test explanation of EMG by mailing a pamphlet before the EMG appointment had no effect on most measures of pain perception and anxiety levels. ${ }^{5}$ Disclosure of pretest information for other tests and procedures has frequently not had a significant impact on pretest anxiety levels, ${ }^{3,6,7}$ though some authors have noted a small effect. ${ }^{8}$ It is important for patients to be fully informed before testing is initiated, but the information may not always alleviate anxiety.

Some of the information given to patients about the painful nature of EMG may have been exaggerated, particularly by those who have limited experience with the test. It is interesting to note that patients who had previous EMGs did not have higher anxiety levels prior to undergoing the test again. If patients received information about the test from poorly informed sources, the information may have focused on aspects of the test for which pre-conceived notions and experiences were common and adverse, such as the use of needles. More than half the patients felt that the test experience was better than they had expected, as noted in other groups. ${ }^{1,9}$ The lack of knowledge about the painful nature of the test resulted in lower pre-test anxiety. Our findings suggest that in discussing the test with patients it is reasonable to be reassuring regarding the degree of pain that may be experienced.

There were potential limitations of our study. Needle EMG was performed on only $49 \%$ of the study patients which may have influenced the number of patients who felt that the test was worse than expected. Needle EMG was not performed routinely in patients with clinically suspected carpal tunnel syndrome who had the condition confirmed with nerve conduction studies, and this was the most frequent condition being evaluated in this group. This conformed to published practice recommendations. ${ }^{10}$ However, needle EMG did not appear to influence 
patient perception of their EMG experience. Similar numbers of patients with or without needle EMG performed felt that the test was better or much better than expected. This factor would not have influenced pre-test anxiety as the patients did not know prior to the test whether a needle exam would be required. Secondly, two-thirds of our cohort were females which may limit the ability to generalize our findings. However, there was no statistically significant association between the anxiety level and gender. Thirdly, we were not able to control for the type of information patients received regarding EMG prior to the study, but as noted above, this may have little influence on pretest anxiety. It was certainly apparent that patients who reported having no prior information about the test were evenly distributed between the high and normal anxiety level groups. The majority of information in the informed group did come from knowledgeable sources and this group had similar numbers of high and normal anxiety patients. However, it is possible that a few small kernels of imprecise information from a friend can have a large influence on pre-test anxiety levels. Finally, 58\% of the patients had an abnormal EMG test result which could have had an impact on anxiety levels, but an abnormal result did not correlate with high anxiety. This was likely the result of the inclusion criteria, as those with a serious underlying disease (e.g. motor neuron disease) were excluded.

In conclusion, we found that patients undergoing EMG were more likely to have high anxiety if they were worried about the test or other aspects of their life, or were taking an antipsychotic or anxiolytic drug. The level of pre-test information received by the patients about the test did not appear to affect anxiety levels, though it is possible that partial and inaccurate information may have contributed to higher anxiety. Fully informing patients about the testing procedures was important, but did not necessarily alleviate anxiety. It is important to provide accurate and essential information in a compassionate manner to patients before any testing procedure is undertaken, but it should be recognized that this may not alleviate anxiety which is influenced by other factors. After the test was completed, the majority of patients reported it was a better experience than they expected. Patients who had a lower anticipation of pain from the test had less anxiety. These findings should be helpful for counseling patients prior to EMG testing.

\section{REFERENCES}

1. Khoshbin S, Hallett M, Lunbeck R. Predictors of patients experience of pain in EMG. Muscle Nerve 1987; 10:629-632.

2. Spielberger CD. Manual for the State-Trait Anxiety Inventory. Palo Alto, CA: Consulting Psychologists Press, 1983.

3. Hopper KD, Houts PS, TenHave TR, Matthews YL, Colon E, et al. The effect of informed consent on the level of anxiety in patients given IVcontrast material. Am J Radiol 1994; 162:531-535.

4. Dean A, Dean J, Burton A, Dicker R. Epi Info: a general-purpose microcomputer program for public health information systems. Am J Prev Med 1991; 7:178-182.

5. Richardson JK, Evans JE, Warner JH. Information effect on perception of pain during electromyography. Arch Phys Med Rehabil 1994; 75:671-675.

6. Lynn-McHale D, Corsetti A, Brady-Avis E, Shaffer R, McGrory J, et al. Preoperative ICU tours: are they helpful? Am J Crit Care 1997; 6:106-115.

7. Inglis $\mathrm{S}$, Farnill $\mathrm{D}$. The effects of providing preoperative statistical anaesthetic-risk information. Anaesth Intensive Care 1993; 21:799-805.

8. Goldberger JJ, Kruse J, Parker MA, Kadish AH. Effect of informed consent on anxiety in patients undergoing diagnostic electrophysiology studies. Am Heart J 1997; 134:119-126.

9. Kothari MJ, Preston DC, Plotkin GM, Venkatesh S, Shefner JM, et al. Electromyography: do the diagnostic ends justify the means? Arch Phys Med Rehabil 1995; 76:947-949.

10. American Association of Electrodiagnostic Medicine. Practice parameter for electrodiagnostic studies in carpal tunnel syndrome: Summary Statement. Muscle Nerve 1993; 16: 1390 1391. 